\title{
Anti-diarrheal effect of Scutellaria baicalensis is associated with suppression of smooth muscle in the rat colon
}

\author{
HYUN JU KIM ${ }^{1}$, JUN-HO LA ${ }^{2}$, HEE MAN KIM ${ }^{3,4}$, IL-SUK YANG ${ }^{1}$ and TAE SIK SUNG \\ ${ }^{1}$ Department of Veterinary Physiology, College of Veterinary Medicine, Seoul National University, Seoul 08826, Republic of Korea; \\ ${ }^{2}$ Department of Neuroscience, Cell Biology and Anatomy, University of Texas Medical Branch, Galveston, TX 77555, USA; \\ ${ }^{3}$ Department of Internal Medicine, Yonsei University Wonju College of Medicine, Wonju 26426, Republic of Korea; \\ ${ }^{4}$ Department of Physiology and Cell Biology, University of Nevada, Reno School of Medicine, Reno, NV 89557-0357, USA
}

Received October 18, 2018; Accepted March 19, 2019

DOI: $10.3892 /$ etm.2019.7469

\begin{abstract}
Scutellaria baicalensis (S. baicalensis) has been used to manage diarrhea, and its anti-inflammatory effects are responsible for anti-diarrheal effects. However, there are no data concerning its direct effect on colonic motility. Therefore, the effects of the major components of S. baicalensis (baicalin, baicalein and wogonin) on colonic motility were investigated. A segment of the distal colon of rats was placed in Krebs solution to monitor spontaneous giant contractions (GCs). Changes in GCs were recorded after applying baicalin, baicalein or wogonin. After pretreatment with $\mathrm{N}^{\omega}$-nitro-L-arginine methyl ester hydrochloride (L-NAME), 1H-(1,2,4)-oxadiazolo (4,2-a) quinoxalin-1-one (ODQ), tetradotoxin, w-conotoxin, apamin, and iberiotoxin, changes in GCs by wogonin were recorded and analyzed. The segment of the distal colon showed spontaneous GCs at a mean amplitude of $3.7 \pm 0.3 \mathrm{~g}$ with a frequency of $0.8 \pm 0.1 / \mathrm{min}$. Baicalin, baicalein, and wogonin reduced both the amplitude and the frequency of GCs in a dose-dependent manner. Wogonin had the most potent inhibitory effect on GCs ( $\mathrm{IC}_{50}$ was $14.6 \mu \mathrm{M}$ in amplitude and $14.2 \mu \mathrm{M}$ in frequency). Wogonin-induced GC reduction was not significantly affected by the inhibition of nitric oxide/cGMP pathways with L-NAME and ODQ. Blocking the enteric neurotransmission with tetradotoxin and $\omega$-conotoxin was ineffective on the wogonin-induced reduction of $\mathrm{GCs}$. $\mathrm{Ca}^{2+}$-activated $\mathrm{K}^{+}$ $\left(\mathrm{K}_{\mathrm{Ca}}\right)$ channel blockers (apamin and iberiotoxin) significantly attenuated the inhibitory effects of wogonin on GCs $(\mathrm{P}<0.01)$. Wogonin was effective in inhibiting colonic motility, probably through the opening of $\mathrm{K}_{\mathrm{Ca}}$ channels located in the smooth muscle apparatus. These findings suggest that wogonin may
\end{abstract}

Correspondence to: Dr Tae Sik Sung, Department of Physiology and Cell Biology, University of Nevada, Reno School of Medicine, 1664 North Virginia Street, Reno, NV 89557-0357, USA

E-mail: tsung@medicine.nevada.edu

Key words: Scutellaria baicalensis, wogonin, diarrhea, giant contractions, $\mathrm{Ca}^{2+}$-activated $\mathrm{K}^{+}$channel be a candidate drug for the management of dysmotility-related diarrhea.

\section{Introduction}

Diarrhea is categorized into four types based on its mechanism of action: Osmotic diarrhea, secretory diarrhea, inflammatory and infectious diarrhea, and diarrhea related to motility disorders. Clinically, diarrhea-predominant irritable bowel syndrome and functional diarrhea are associated with alterations in intestinal motility; therefore, some anti-diarrheal agents decreasing intestinal transit, such as opioids and $5-\mathrm{HT}_{3}$ antagonist, have been used to manage these diseases (1).

Scutellaria baicalensis is widely used as a herbal medicine in East Asia and Europe for gastrointestinal tract (GI) disorders including dysentery, diarrhea, and abdominal pain (2). Experimentally, it has anti-diarrheal effect on irrinotecan-induced diarrhea in rats (3). Clinically, it demonstrated an improvement in the diarrhea toxicity grade and reduction of frequency of severe diarrhea in lung cancer patients with irrinotecan-induced diarrhea (4). Baicalin, a component of $S$. baicalensis has anti-diarrheal action through its anti-inflammatory effects inhibiting cyclooxygenase-2 (COX-2) activity and colonic prostaglandin $\mathrm{E}_{2}\left(\mathrm{PGE}_{2}\right)(5,6)$. However, it is still unknown whether $S$. baicalensis directly modulates bowel motility.

Bowel motility is the result of a coordinated contraction and relaxation of intestinal smooth muscles, which is regulated by various neurotransmitters. The neuroeffector apparatus in the GI muscles is conceptualized as the SIP syncytium composed of electrically coupled smooth muscle cells (SMC), interstitial cells of Cajal (ICC), and platelet-derived growth factor receptor $\alpha$ positive (PDGFR $\alpha^{+}$) cells. Various receptors and ion channels are expressed in SIP cells, and conductance changes in any type of SIP cells affect the integrated excitability of muscle layers and responses to neurotransmitters (7).

We hypothesized that if the components of S. baicalensis could alter the bowel motility, it is conceivable that they affect the neuromuscular transmission and/or the excitability of SIP cells. Therefore, we examined the effect of the major components of S. baicalensis on colonic motility, and investigated 
the mechanism of action of the components on smooth muscle of rat colon.

\section{Materials and methods}

Animal and tissue preparation. Male Sprague-Dawley rats (250 300 g), provided ad libitum standard chow and water, were used for this study. The rats were housed in stainless steel hanging cages in a colony room maintained under a $12 \mathrm{~h}$ light/dark cycle with a room temperature of $21-23^{\circ} \mathrm{C}$ and humidity of $65-70 \%$. Their care and handling were in accordance with the NIH Guide for the Care and Use of Laboratory Animals. All procedures were approved by the Institutional Animal Use and Care Committee at the Seoul National University (Seoul, Korea; approval no. SNU-101872-04). Rats were anesthetized with isoflurane followed by cervical dislocation. From these rats, $2.5-3 \mathrm{~cm}$ distal colons were removed and flushed clean with Krebs solution. The colonic segments were immediately placed in a $20 \mathrm{ml}$ organ bath containing Krebs solution bubbled with a mixture of $5 \% \mathrm{CO}_{2}-95 \% \mathrm{O}_{2}$ $(\mathrm{pH} 7.4)$ at $37^{\circ} \mathrm{C}$. The preparations were given a minimum of 60-90 min to equilibrate before commencing the experiments. During this period, spontaneous rhythmic giant contractions (GCs) were developed and stabilized.

Measurement of colonic motility. The distal end of the colonic segment was tied to a fixed mount, and the ligated proximal end was secured with silk thread to an isometric force displacement transducer (FT-03; Grass-Telefactor; Astro Med, Inc., Slough, UK). Changes in mechanical signals were detected as isometric tension and recorded as an index of the longitudinal muscle response. After the equilibrium period, spontaneous GCs were recorded. The components of $S$. baicalensis and chemicals were added to the organ bath, after which spontaneous GCs were recorded.

Solutions and chemicals. Krebs solution contained (mM) 10.10 glucose, $115.48 \mathrm{NaCl}, 21.90 \mathrm{NaHCO}_{3}, 4.61 \mathrm{KCl}$, $1.14 \mathrm{NaH}_{2} \mathrm{PO}_{4}, 2.5 \mathrm{CaCl}_{2}$, and $1.16 \mathrm{MgSO}_{4}$. The following chemicals were used: $\mathrm{N}^{\omega}$-nitro-L-arginine methyl ester hydrochloride (L-NAME; $300 \mu \mathrm{M}), 1 \mathrm{H}-(1,2,4)$-oxadiazolo $(4,2-\mathrm{a})$ quinoxalin-1-one (ODQ; $10 \mu \mathrm{M}$ ), tetradotoxin (TTX; $1 \mu \mathrm{M}$ ), $\omega$-conotoxin $(300 \mathrm{nM})$, apamin $(100 \mathrm{nM})$, and iberiotoxin (100 nM). Each drug was administered 15 min before adding wogonin. Concentrated stock solutions of L-NAME, TTX, $\omega$-conotoxin, apamin, iberiotoxin (Sigma-Aldrich; Merck KGaA, Darmstadt, Germany) were prepared by dissolving the chemicals in distilled water. ODQ (Sigma-Aldrich; Merck KGaA) was dissolved in dimethyl sulfoxide (DMSO). Baicalin, baicalein and wogonin (Sigma-Aldrich; Merck KGaA) were prepared in $0.2 \mathrm{~N} \mathrm{NaOH}$. When DMSO was previously used as a solvent for concentrated stock solutions of baicalin, baicalein, and wogonin, they recrystallized at high doses in Krebs solution and we were unable to measure the exact working concentration. Therefore, in this study, $0.2 \mathrm{~N} \mathrm{NaOH}$ was used as the solvent to overcome the problem. The dose of baicalin, baicalein, and wogonin was chosen between subminimal and submaximal inhibitory effect of drugs. Even though $500 \mu \mathrm{M}$ was not submaximal dose of baicalin, highest dose of baicalin was determined at $500 \mu \mathrm{M}$ due to be recrystallized at over $500 \mu \mathrm{M}$.
TTX was used to block the enteric impulse in the rat colon smooth muscle. $\omega$-conotoxin was used to block the neurotransmitter release from nerve terminals by blocking the N-type $\mathrm{Ca}^{2+}$ channels (8). Apamin was used to block a small-conductance $\mathrm{Ca}^{2+}$-activated $\mathrm{K}^{+}$(SK) channel, which are located in PDGFR $\alpha^{+}$cells dominantly in the smooth muscle apparatus. Iberiotoxin was used to block a large-conductance $\mathrm{Ca}^{2+}$-activated $\mathrm{K}^{+}(\mathrm{BK})$ channel, expressed in the SMCs.

Analysis of data. The recorded amplitude and frequency of GCs were analyzed. Two segments from one mouse colon were prepared because some of pretreated drugs were not washed completely. Therefore, we separately analyzed each dataset. To measure the effects of the drug on GCs, each experimental measurement was matched with a control measurement in the same tissue. The amplitude and frequency of GCs in the control state were considered $100 \%$ and the parameters of GCs in the presence of baicalin, baicalein, and wogonin were expressed as percentage of the control. For the fitting of the concentration response curves of the $S$. baicalensis components, the following logisticcal function was used; $\mathrm{Y}=100 /\left\{1+10^{\wedge}\left[\left(\mathrm{IC}_{50}-\mathrm{C}\right) \mathrm{h}\right]\right\}$, where $\mathrm{Y}$ is the normalized $(\%)$ $\mathrm{GC}$ amplitude or frequency at a given concentration (C) of each substance, and $h$ is the slope factor of the curve. $\mathrm{IC}_{50}$ was defined as the concentration of the substance at which $\mathrm{Y}$ was inhibited to $50 \%$ of the GC amplitude or frequency in the control state. Data were expressed as means \pm SEM of $\mathrm{n}$, the number of tissues. Statistical analysis was primarily performed by 2 -way repeated measures ANOVA followed by Holm-Sidak multiple comparison test. $\mathrm{P}<0.05$ was considered significant differences.

\section{Results}

Inhibitory effect of baicalin, baicalein, and wogonin on $G C s$ in the rat colon. Spontaneous GCs occurred at a mean amplitude of $3.7 \pm 0.3 \mathrm{~g}$ with a frequency of $0.8 \pm 0.1 / \mathrm{min}$ in the distal colon of rats $(n=38)$. As shown in Fig. 1, three major components of $S$. baicalensis, namely baicalin ( $\mathrm{n}=14)$, baicalein $(n=12)$ and wogonin $(n=12)$, reduced the amplitude and frequency of GCs in a dose-dependent manner. After washing off the drugs, the GCs showed complete recovery. The $\mathrm{IC}_{50}$ value of baicalin was $545.4 \mu \mathrm{M}$ in amplitude and $463.3 \mu \mathrm{M}$ in frequency. The $\mathrm{IC}_{50}$ value of baicalein was $112.9 \mu \mathrm{M}$ in amplitude and $123.9 \mu \mathrm{M}$ in frequency. The $\mathrm{IC}_{50}$ value of wogonin was $14.6 \mu \mathrm{M}$ in amplitude and $14.2 \mu \mathrm{M}$ in frequency (Table I). These results show that wogonin is the most effective agent among the three substances in inhibiting GCs in the distal colon of rats.

No effect of nitrergic inhibitory pathway on the wogonin-induced reduction of GCs. In order to evaluate whether wogonin-induced reduction of GCs was mediated by nitric oxide (NO), the NO synthesis inhibitor, L-NAME (300 $\mu \mathrm{M})$, was used for pre-treatment prior to applying increasing concentrations of wogonin. When comparing the presence and absence of L-NAME, no significant difference in the wogonin-induced reduction of GC amplitude $\left(\mathrm{F}_{(1,10)}=0.99\right.$, $\mathrm{P}=0.341)$ and frequency $\left(\mathrm{F}_{(1,11)}=1.01, \mathrm{P}=0.336\right)$ (Fig. 2A-C) $(n=6-7)$ could be observed. 
Table I. Effects of baicalin, baicalein, and wogonin on the amplitude and frequency of the giant contractions in rat colon (mean \pm standard error of the mean).

A. Amplitude

\begin{tabular}{|c|c|c|c|c|c|}
\hline Dose $(\mu \mathrm{M})$ & Baicalin (\%) & Dose $(\mu \mathrm{M})$ & Baicalein (\%) & Dose $(\mu \mathrm{M})$ & Wogonin $(\%)$ \\
\hline 30 & $97.0 \pm 3.2$ & 3 & $96.6 \pm 7.5$ & 1 & $95.4 \pm 1.1$ \\
\hline 100 & $94.0 \pm 6.1$ & 10 & $94.6 \pm 3.4$ & 3 & $90.2 \pm 3.2$ \\
\hline 300 & $79.0 \pm 7.2$ & 30 & $93.0 \pm 6.4$ & 10 & $72.7 \pm 8.0$ \\
\hline \multirow[t]{2}{*}{500} & $53.3 \pm 12.6$ & 100 & $64.4 \pm 9.1$ & 20 & $24.7 \pm 9.6$ \\
\hline & & 300 & 0 & 30 & $3.8 \pm 3.8$ \\
\hline P-value & $\mathrm{P}<0.001$ & & $\mathrm{P}<0.001$ & & $\mathrm{P}<0.001$ \\
\hline $\mathrm{IC}_{50}(\mu \mathrm{M})$ & 545.4 & & 112.9 & & 14.6 \\
\hline
\end{tabular}

B. Frequency

\begin{tabular}{|c|c|c|c|c|c|}
\hline Dose $(\mu \mathrm{M})$ & Baicalin (\%) & Dose $(\mu \mathrm{M})$ & Baicalein (\%) & Dose $(\mu \mathrm{M})$ & Wogonin (\%) \\
\hline 30 & $93.5 \pm 25.2$ & 3 & $100.3 \pm 4.1$ & 1 & $89.1 \pm 5.1$ \\
\hline 100 & $88.2 \pm 7.6$ & 10 & $82.5 \pm 5.4$ & 3 & $86.5 \pm 8.6$ \\
\hline 300 & $61.0 \pm 6.3$ & 30 & $80.4 \pm 2.9$ & 10 & $65.5 \pm 4.8$ \\
\hline \multirow[t]{2}{*}{500} & $46.5 \pm 11.7$ & 100 & $71.3 \pm 6.3$ & 20 & $22.6 \pm 8.0$ \\
\hline & & 300 & 0 & 30 & $11.7 \pm 8.3$ \\
\hline P-value & $\mathrm{P}<0.001$ & & $\mathrm{P}<0.001$ & & $\mathrm{P}<0.001$ \\
\hline $\mathrm{IC}_{50}(\mu \mathrm{M})$ & 463.3 & & 123.9 & & 14.2 \\
\hline
\end{tabular}
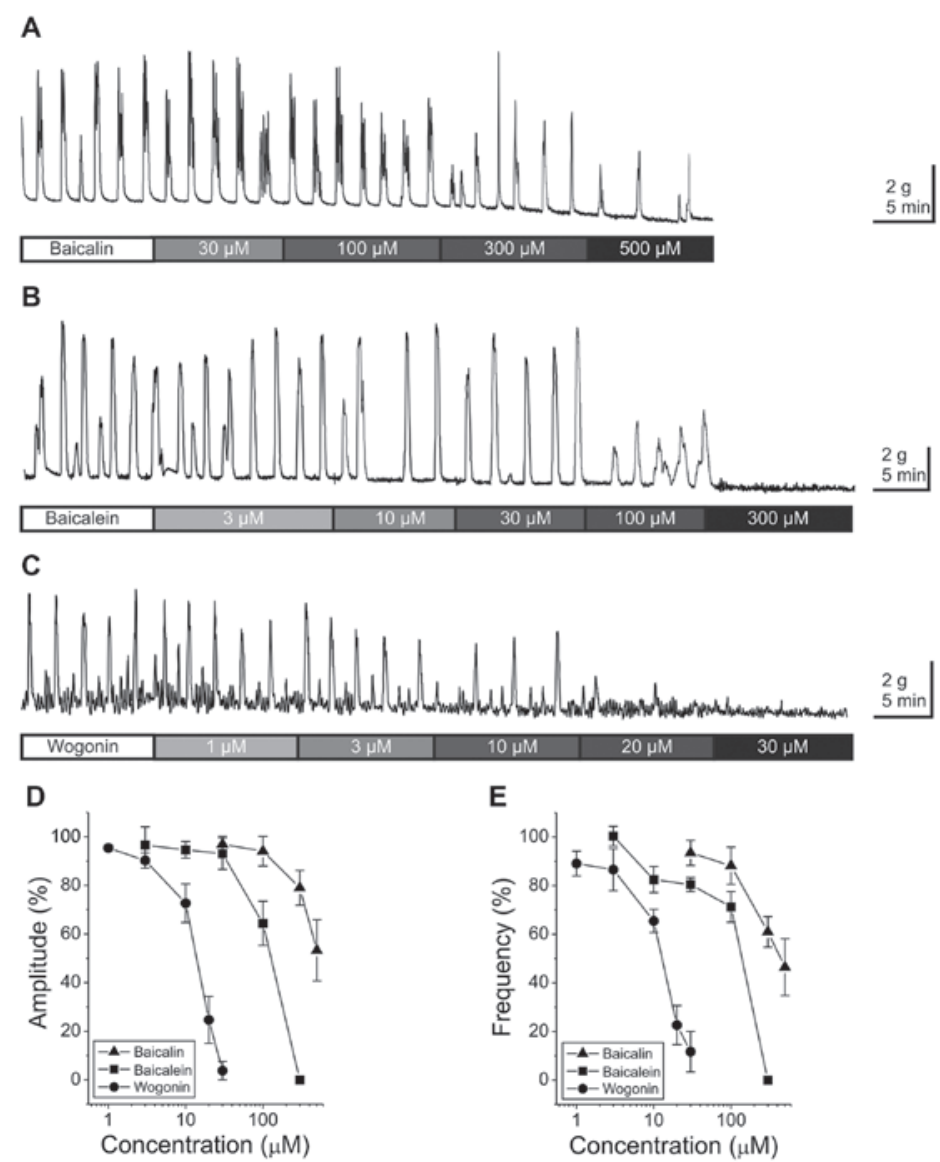

Figure 1. Comparison of the effects of major components of Scutellaria baicalensis on the spontaneous GCs. (A) Baicalin, (B) Baicalein and (C) Wogonin reduced the amplitude and frequency of GCs in a dose-dependent manner. Dose-response plots showing inhibitory effect of the three S. baicalensis components on the (D) amplitude and (E) frequency of GCs. GCs, giant contractions. 

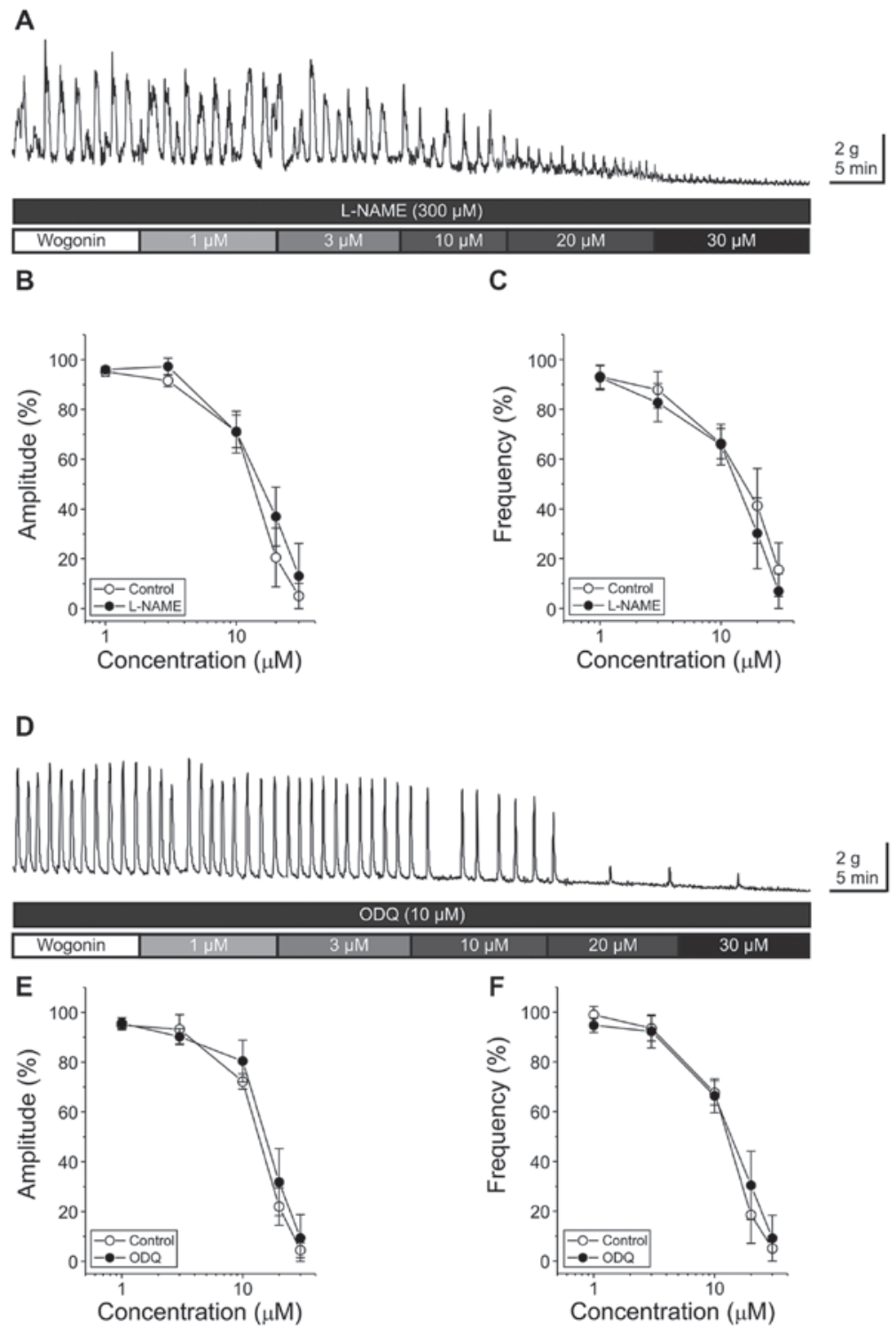

Figure 2. Reduction of the spontaneous GCs by wogonin in the presence of L-NAME or ODQ. (A) Representative traces showing that wogonin reduced GCs in the presence of L-NAME. Dose-response plots showing the effects of (B and C) L-NAME on wogonin-induced reduction of the amplitude and frequency of GCs. (D) Representative traces showing that wogonin reduced GCs in the presence of ODQ. Dose-response plots showing the effects of (E and F) ODQ on wogonin-induced reduction of the amplitude and frequency of GCs. GCs, giant contractions; L-NAME, NW-nitro-L-arginine methyl ester hydrochloride; ODQ, 1H-(1,2,4)-oxadiazolo (4,2-a) quinoxalin-1-one.

An inhibitor of soluble guanylyl cyclase, ODQ, was used to examine the involvement of cGMP in the wogonin-induced reduction of GCs. The pretreatment with ODQ $(10 \mu \mathrm{M})$ did not affect the inhibitory effect of wogonin on the amplitude $\left(\mathrm{F}_{(1,9)}=0.485, \mathrm{P}=0.504\right)$ and the frequency $\left(\mathrm{F}_{(1,9)}=0.259\right.$, $\mathrm{P}=0.623)$ of GCs (Fig. 2D-F) $(\mathrm{n}=5-6)$.

No involvement of enteric neurotransmission in the wogonin-induced reduction of GCs. To evaluate whether wogonin-induced reduction of GCs was dependent on the activation of the enteric nervous system, TTX or $\omega$-conotoxin were pretreated before applying wogonin. In the six distal colon pretreated with TTX $(1 \mu \mathrm{M})$, the application of wogonin at 1,3, 10,20 , and $30 \mu \mathrm{M}$ did not show any significant changes in the amplitude $\left(\mathrm{F}_{(1,10)}=0.181, \mathrm{P}=0.679\right)$ and frequency $\left(\mathrm{F}_{(1,9)}=0.498\right.$, $\mathrm{P}=0.498$ ), compared to those observed in the control devoid of pretreatment with TTX (Fig. 3A-C).
In the five distal colon pretreated with $\omega$-conotoxin (300 $\mathrm{nM}$ ), the application of wogonin at 1,3,10,20, and $30 \mu \mathrm{M}$ did not cause any significant changes in the amplitude $\left(\mathrm{F}_{(1.8)}=0.118, \mathrm{P}=0.740\right)$ and frequency $\left(\mathrm{F}_{(1.8)}=0.757, \mathrm{P}=0.409\right)$, compared to those observed in the control devoid of pretreatment with $\omega$-conotoxin (Fig. 3D-F).

Involvement of $\mathrm{Ca}^{2+}$-activated $\mathrm{K}^{+}$channels in the wogonin-induced reduction of GCs. The $\mathrm{Ca}^{2+}$-activated $\mathrm{K}^{+}$channel $\left(\mathrm{K}_{\mathrm{Ca}}\right)$ channel blockers, apamin and iberiotoxin were used to investigate the participation of $\mathrm{K}_{\mathrm{Ca}}$ channels in wogonin-induced reduction of GCs. The pretreatment with apamin $(100 \mathrm{nM})$ partially but significantly inhibited the wogonin $(20$ and $30 \mu \mathrm{M})$-induced reduction of GCs (Tables II and III) (Fig. 4A-C) $(\mathrm{n}=12-15)$. Similarly, the pretreatment with iberiotoxin $(100 \mathrm{nM})$ also partially inhibited the wogonin $(20$ and $30 \mu \mathrm{M})$-induced reduction 

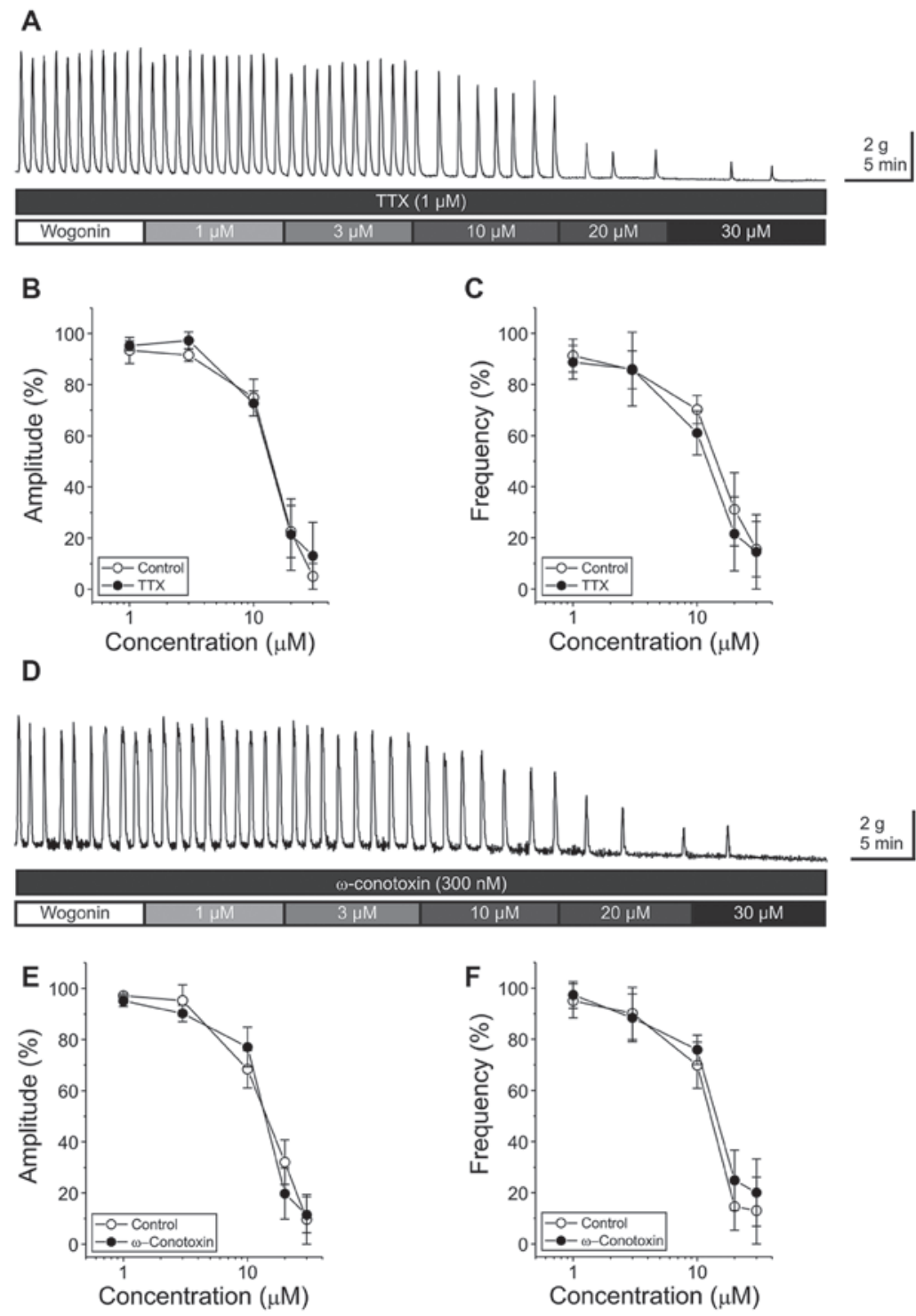

Figure 3. Reduction of the spontaneous GCs by wogonin in the presence of TTX or $\omega$-conotoxin. (A) Representative traces showing that wogonin reduced GCs in a dose-dependent manner in the presence of TTX. Plotting the response at various doses showing the effects of (B and C) TTX on wogonin-induced reduction of GCs. (D) Representative traces showing that wogonin reduced GCs in a dose-dependent manner in the presence of $\omega$-conotoxin. Plotting the response at various doses showing the effects of (E and F) $\omega$-conotoxin on wogonin-induced reduction of GCs. GCs, giant contractions; TTX, tetradotoxin.

of GCs (Tables II and III) (Fig. 4D-F) (n=5-6). Following pretreatment with apamin plus iberiotoxin (Table IV) (Fig. 5), wogonin had no statistically significant inhibitory effect on the amplitude and frequency of GC.

\section{Discussion}

This study demonstrates that the three major flavonoids of $S$. baicalensis, baicalin, baicalein and wogonin, inhibit the colonic spontaneous motility in a dose-dependent manner in the rat colon. Of the three substances, wogonin was the most effective in inhibiting GCs. This inhibitory effect of wogonin is associated with $\mathrm{K}_{\mathrm{Ca}}$ channels in the smooth muscle.

In the aortic and mesenteric arterial smooth muscles, baicalin and baicalein were found to be related to NO-mediated responses and cGMP regulation (9). NO/cGMP pathway is the main physiological mechanism that modulates intestinal motility of both, the duration and amplitude of GCs.
NO activates soluble guanylyl cyclase and produces cGMP to relax the smooth muscles by lowering the cytosolic calcium levels and/or by reducing the sensitivity of the contractile elements to calcium (10-13). The association with NO in GCs raised the possibility that wogonin suppresses GCs by increasing the NO release. However, in our study, L-NAME did not affect the wogonin-induced reduction of GCs, which is consistent with a previous report in the aorta (14). Furthermore, a soluble guanylyl cyclase inhibitor, ODQ, also did not affect the inhibitory action of wogonin on GCs. These results indicate that wogonin neither stimulates NO production nor enhances the cGMP-dependent mechanisms in the suppression of GCs.

Other inhibitory enteric neurotransmitters also appear to not mediate the wogonin-induced reduction of GCs. In our study, wogonin still effectively reduced the GCs in the presence of either TTX or $\omega$-conotoxin. These findings suggest that the inhibitory effect of wogonin is not associated with activating 
Table II. Effects of SK channel blockers on the wogonin-induced reduction of the GCs (mean \pm standard error of the mean).

\begin{tabular}{|c|c|c|c|c|c|c|}
\hline \multirow[b]{2}{*}{ Dose $(\mu \mathrm{M})$} & \multicolumn{3}{|c|}{ Amplitude } & \multicolumn{3}{|c|}{ Frequency } \\
\hline & Control (\%) & Apamin (\%) & P-value & Control (\%) & Apamin (\%) & P-value \\
\hline 1 & $95.4 \pm 1.1$ & $93.2 \pm 1.0$ & 0.769 & $89.1 \pm 5.1$ & $90.4 \pm 2.1$ & 0.865 \\
\hline 3 & $90.2 \pm 3.2$ & $87.5 \pm 1.9$ & 0.915 & $86.5 \pm 8.6$ & $84.9 \pm 5.0$ & 0.602 \\
\hline 10 & $72.7 \pm 8.0$ & $80.5 \pm 3.0$ & 0.26 & $65.5 \pm 4.8$ & $72.5 \pm 6.2$ & 0.739 \\
\hline 20 & $24.7 \pm 9.6$ & $59.7 \pm 6.8$ & $<0.001^{\mathrm{b}}$ & $22.6 \pm 8.0$ & $56.5 \pm 7.5$ & $<0.001^{\mathrm{b}}$ \\
\hline 30 & $3.8 \pm 3.8$ & $56.2 \pm 8.0$ & $0.003^{\mathrm{b}}$ & $11.7 \pm 8.3$ & $45.4 \pm 6.4$ & $0.049^{\mathrm{a}}$ \\
\hline
\end{tabular}

${ }^{\mathrm{a}} \mathrm{P}<0.05,{ }^{\mathrm{b}} \mathrm{P}<0.01$ by Holm-Sidak test. GCs, giant contractions.

Table III. Effects of BK channel blockers on the wogonin-induced reduction of the GCs (mean \pm standard error of the mean).

\begin{tabular}{|c|c|c|c|c|c|c|}
\hline \multirow[b]{2}{*}{ Dose } & \multicolumn{3}{|c|}{ Amplitude } & \multicolumn{3}{|c|}{ Frequency } \\
\hline & Control (\%) & Iberiotoxin (\%) & P-value & Control (\%) & Iberiotoxin (\%) & P-value \\
\hline 1 & $93.9 \pm 7.6$ & $91.8 \pm 0.7$ & 0.845 & $93.6 \pm 4.7$ & $89.9 \pm 7.8$ & 0.787 \\
\hline 3 & $94.0 \pm 9.3$ & $95.0 \pm 1.5$ & 0.925 & $88.4 \pm 9.3$ & $88.6 \pm 9.5$ & 0.989 \\
\hline 10 & $74.3 \pm 6.8$ & $89.8 \pm 7.1$ & 0.164 & $66.9 \pm 11.1$ & $77.9 \pm 11.9$ & 0.44 \\
\hline 20 & $33.9 \pm 11.5$ & $81.5 \pm 10.7$ & $<0.001^{\mathrm{b}}$ & $29.5 \pm 8.0$ & $71.7 \pm 12.7$ & $0.012^{\mathrm{a}}$ \\
\hline 30 & $6.7 \pm 6.7$ & $61.8 \pm 7.6$ & $<0.001^{\mathrm{b}}$ & $8.8 \pm 8.8$ & $53.5 \pm 6.1$ & $0.009^{\mathrm{b}}$ \\
\hline
\end{tabular}

${ }^{\mathrm{a}} \mathrm{P}<0.05,{ }^{\mathrm{b}} \mathrm{P}<0.01$ by Holm-Sidak test. $\mathrm{BK}$ channel, large-conductance $\mathrm{Ca}^{2+}$-activated $\mathrm{K}^{+}$channel; GCs, giant contractions .

Table IV. Effects of the combined pre-treatment of SK and BK channel blockers on the wogonin-induced reduction of the giant contractions (mean \pm standard error of the mean).

\begin{tabular}{|c|c|c|c|c|c|c|}
\hline \multirow[b]{2}{*}{ Dose $(\mu \mathrm{M})$} & \multicolumn{3}{|c|}{ Amplitude } & \multicolumn{3}{|c|}{ Frequency } \\
\hline & Control (\%) & Apa+Ibe (\%) & P-value & Control (\%) & Apa+Ibe (\%) & P-value \\
\hline 1 & $98.7 \pm 1.5$ & $97.6 \pm 0.5$ & 0.914 & $95.3 \pm 4.2$ & $93.9 \pm 1.5$ & 0.941 \\
\hline 3 & $92.4 \pm 2.5$ & $98.2 \pm 1.0$ & 0.592 & $89.8 \pm 5.8$ & $94.7 \pm 5.9$ & 0.823 \\
\hline 10 & $74.0 \pm 6.3$ & $95.8 \pm 3.6$ & 0.053 & $70.0 \pm 7.3$ & $93.2 \pm 5.0$ & 0.072 \\
\hline 20 & $21.8 \pm 13.9$ & $88.4 \pm 4.5$ & $<0.010^{\mathrm{a}}$ & $20.7 \pm 11.0$ & $86.6 \pm 7.0$ & $<0.001^{\mathrm{a}}$ \\
\hline 30 & $10.1 \pm 10.1$ & $82.6 \pm 6.1$ & $<0.010^{\mathrm{a}}$ & $13.8 \pm 9.2$ & $81.0 \pm 8.8$ & $<0.001^{\mathrm{a}}$ \\
\hline
\end{tabular}

${ }^{\mathrm{a}} \mathrm{P}<0.01$ by Holm-Sidak test. SK channel, small-conductance $\mathrm{Ca}^{2+}$-activated $\mathrm{K}^{+}$channel; $\mathrm{BK}$ channel, large-conductance $\mathrm{Ca}^{2+}$-activated $\mathrm{K}^{+}$ channel; Apa+Ibe; apamin plus iberiotoxin.

the inhibitory enteric neural pathways such as NO/cGMP system. Rather, wogonin seems to directly inhibit the smooth muscle contractility to suppress GCs.

Smooth muscle can generate spontaneous GC without neural input, which is termed myogenic contraction. In the tunica muscularis of the colon, SMCs contact ICC and PDGFR $\alpha^{+}$cells through a gap junction, resulting in the formation of a SIP syncytium. The SIP syncytium is responsible for the motility of GI muscles classically referred to in the literature as 'myogenic' $(15) . \mathrm{K}^{+}$channels play an important role in the regulation of contractility, and opening of $\mathrm{K}^{+}$channels contribute to the relaxing effect of various relaxants (16-19). Among the $\mathrm{K}^{+}$channels, $\mathrm{K}_{\mathrm{Ca}}$ channels in the smooth muscles are the important negative feedback elements in limiting the extracellular $\mathrm{Ca}^{2+}$ influx-mediated smooth muscle contraction $(20,21)$. Two types of $\mathrm{K}_{\mathrm{Ca}}$ are identified in smooth muscles: SK channels sensitive to apamin and BK channels sensitive to iberiotoxin $(22,23)$.

Considering the roles of $\mathrm{K}_{\mathrm{Ca}}$ channels in smooth muscle contractility, it could be hypothesized that $\mathrm{K}_{\mathrm{Ca}}$ channels might participate in the wogoinin-induced reduction of GCs. Based on the results of the experiment to test this hypothesis, we 

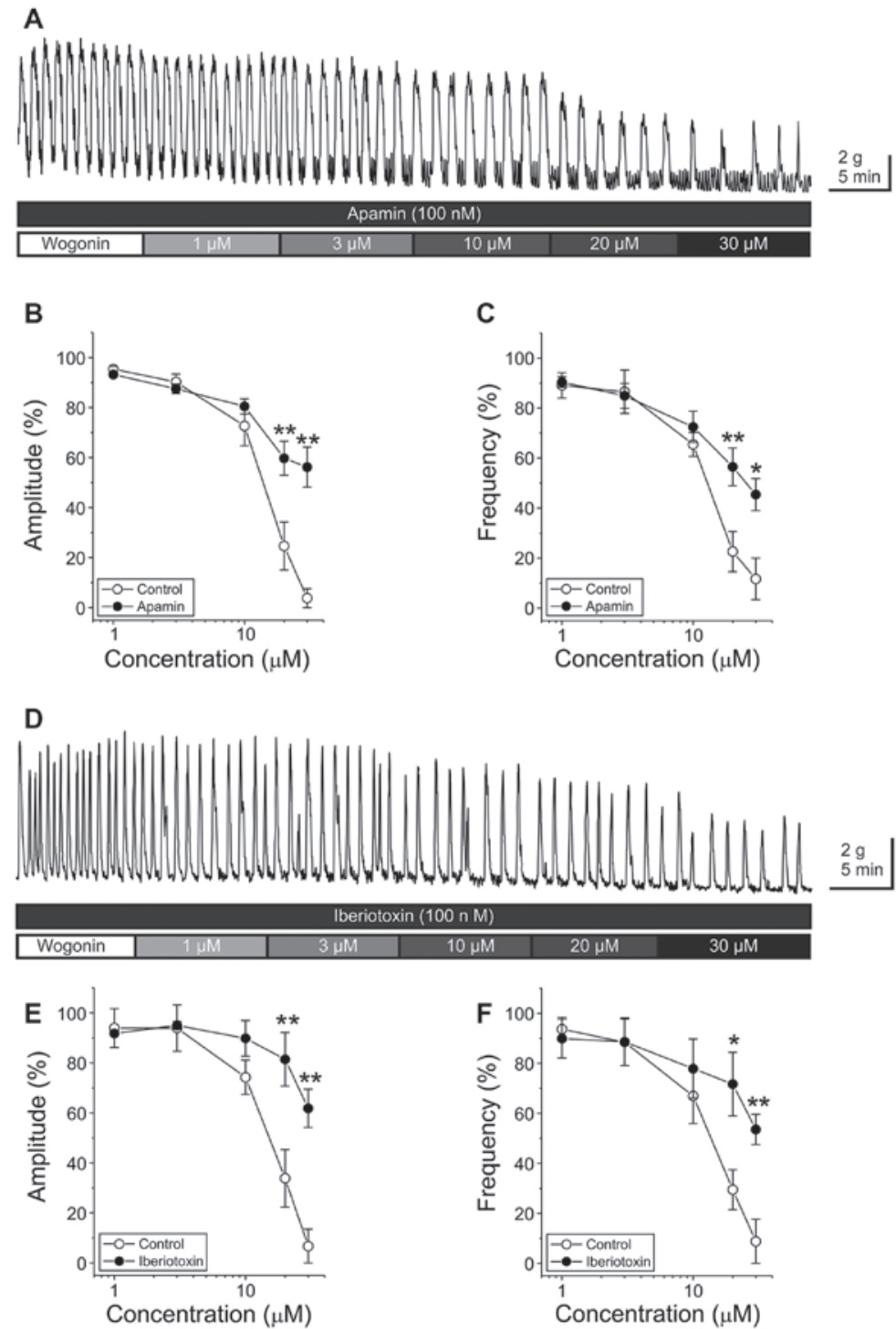

Figure 4. Inhibitory effects of SK or BK channel blockers on wogonin-induced reduction of the spontaneous GCs. (A-F) Wogonin-induced reduction of the amplitude and frequency of GCs was partially inhibited in the presence of SK channel blocker, apamin or in the presence of BK channel blocker, iberiotoxin. "P<0.05; ${ }_{* * *} \mathrm{P}<0.01$ vs. control. GCs, giant contractions; $\mathrm{SK}$ channel, small-conductance $\mathrm{Ca}^{2+}$-activated $\mathrm{K}^{+}$channel; BK channel, large-conductance $\mathrm{Ca}^{2+}$-activated $\mathrm{K}^{+}$channel.
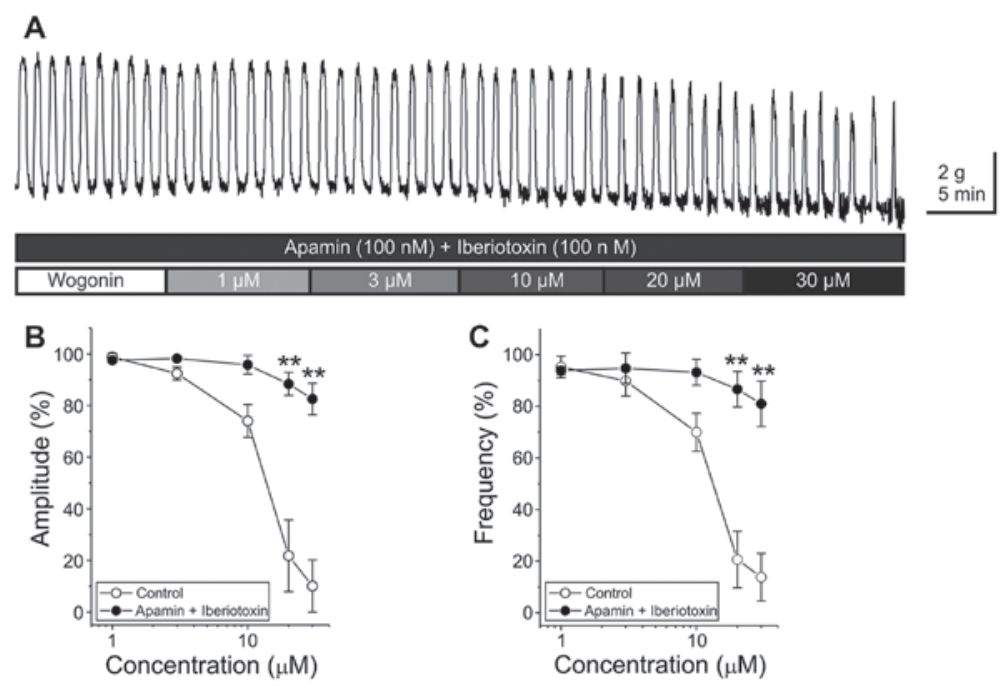

Figure 5. Inhibitory effects of both SK and BK channel blockers on wogonin-induced reduction of the spontaneous GCs. (A) Representative trace showing the effect of wogonin on GCs in the presence of SK and BK channel blockers. When the two types of $\mathrm{K}_{\mathrm{Ca}}$ channels are blocked at the same time, wogonin had no statistically significant inhibitory effect on the (B) amplitude and (C) frequency of GCs. ${ }^{* *} \mathrm{P}<0.01$ vs. control. GCs, giant contractions; SK channel, small-conductance $\mathrm{Ca}^{2+}$-activated $\mathrm{K}^{+}$channel; $\mathrm{BK}$ channel, large-conductance $\mathrm{Ca}^{2+}$-activated $\mathrm{K}^{+}$channel; $\mathrm{K}_{\mathrm{Ca}}$ channel, $\mathrm{Ca}^{2+}$-activated $\mathrm{K}^{+}$channel. 
found that apamin and iberiotoxin significantly attenuated the inhibitory effect of wogonin on GCs. These data indicate that activation of both SK and BK channels are the pivotal processes in the wogonin-induced reduction of GCs. Previous studies have shown that SK channel expression is dominant in PDGFR $\alpha^{+}$cells, although this channel is also present in SMCs (24-28). The current density of SK channels is much higher in PDGFR $\alpha^{+}$cells than in the SMCs $(29,30)$. Unlike the SK channel, the BK channel is known to be expressed in SMCs (31-33). Therefore, it is a possibility that wogonin hyperpolarizes PDGFR $\alpha^{+}$cells via activation of SK channels to lead to $\mathrm{SMC}$ relaxation indirectly, while it hyperpolarizes SMC via activation of BK channels to relax SMC directly. These direct and indirect effects on SMC through different channels result in a reduction of GCs. Wogonin may transiently regulate the intracellular $\mathrm{Ca}^{2+}$ concentration underneath of the membrane through $\mathrm{Ca}^{2+}$ influx or $\mathrm{Ca}^{2+}$ release from the intracellular $\mathrm{Ca}^{2+}$ store in PDGFR $\alpha^{+}$cells and SMCs (35). Therefore, reduction of GCs by wogonin might be induced by the opening of $\mathrm{K}_{\mathrm{Ca}}$ channels directly and/or increase of intracellular $\mathrm{Ca}^{2+}$ concentration underneath of the membrane, and the subsequent opening of $\mathrm{K}_{\mathrm{Ca}}$ channels, which is closely associated with $\mathrm{Ca}^{2+}$ influx channels and/or $\mathrm{Ca}^{2+}$ release site, indirectly.

The components of $S$. baicalensis exert various biological actions, especially anti-inflammation in soft tissues (mucosa, submucosa, and skin), but not in smooth muscle $(34,35)$. It has anti-diarrheal effects on irrinotecan-induced diarrhea $(3,4)$. Baicalin has anti-diarrheal action through inhibiting COX-2 activity and $\mathrm{PGE}_{2}(5,6)$. In our study, wogonin, one of components of $S$. baicalensis, directly inhibited intestinal smooth muscle motility, but not through a mechanism associated with inflammatory pathway. Taken together, this study may provide a completely novel concept of identifying the mechanism of the anti-diarrheal effect of Chinese Skullcap, S. baicalensis. Therefore, the results of this study will serve as a guide to a new therapeutic approach for treatment of acute or chronic diarrhea associated with dysmotility, such as diarrhea-predominant IBS.

In conclusion, our in vitro experiments demonstrated that baicalin, baicalein and wogonin, the components of $S$. baicalensis, inhibited colonic motility. Wogonin, in particular, directly inhibited the colonic smooth muscle through both SK and BK channels, but not via the activation of inhibitory enteric nerves such as the nitrergic nerves. These findings suggest that wogonin may be a candidate drug for the treatment of increased colon motility diseases, such as diarrhea-predominant IBS.

\section{Acknowledgements}

Not applicable.

\section{Funding}

No funding was received.

\section{Availability of data and materials}

The analyzed data sets generated during the study are available from the corresponding author on reasonable request.

\section{Authors' contributions}

HJK, JHL, ISY and TSS conceived the experiments and experimental plan. HJK and TSS performed the experiments. JHL, HMK and TSS collected and analyzed the data. JHL, HMK and TSS wrote the paper. All authors approve the final version of these manuscript and figures.

\section{Ethics approval and consent to participate}

Animal care and handling were in accordance with the NIH Guide for the Care and Use of Laboratory Animals. All procedures were approved by the Institutional Animal Use and Care Committee at the Seoul National University (Seoul, Korea).

\section{Patient consent for publication}

Not applicable.

\section{Competing interests}

The authors declare that they have no conflicts of interest to disclose with regards to this study.

\section{References}

1. Tack J: Functional diarrhea. Gastroenterol Clin North Am 41: 629-637, 2012

2. Zhao Q, Chen XY and Martin C: Scutellaria baicalensis, the golden herb from the garden of Chinese medicinal plants. Sci Bull (Beijing) 61: 1391-1398, 2016.

3. Cui DN, Wang X, Chen JQ, Lv B, Zhang P, Zhang W, Zhang ZJ and Xu FG: Quantitative evaluation of the compatibility effects of huangqin decoction on the treatment of irinotecan-induced gastrointestinal toxicity using untargeted metabolomics. Front Pharmacol 8: 211, 2017.

4. Mori K, Kondo T, Kamiyama Y, Kano Y and Tominaga K: Preventive effect of Kampo medicine (Hangeshashin-to) against irinotecan-induced diarrhea in advanced non-small-cell lung cancer. Cancer Chemother Pharmacol 51: 403-406, 2003.

5. Kase Y, Saitoh K, Makino B, Hashimoto K, Ishige A and Komatsu Y: Relationship between the antidiarrhoeal effects of Hange-Shashin-To and its active components. Phytother Res 13: 468-473, 1999.

6. Kase Y, Hayakawa T, Aburada M, Komatsu Y and Kamataki T: Preventive effects of Hange-shashin-to on irinotecan hydrochloride-caused diarrhea and its relevance to the colonic prostaglandin E2 and water absorption in the rat. Jpn J Pharmacol 75: 407-413, 1997.

7. Sanders KM, Ward SM and Koh SD: Interstitial cells: Regulators of smooth muscle function. Physiol Rev 94: 859-907, 2014.

8. Adams DJ, Smith AB, Schroeder CI, Yasuda T and Lewis RJ: Omega-conotoxin CVID inhibits a pharmacologically distinct voltage-sensitive calcium channel associated with transmitter release from preganglionic nerve terminals. J Biol Chem 278: 4057-4062, 2003.

9. Huang Y, Wong CM, Lau CW, Yao X, Tsang SY, Su YL and Chen ZY: Inhibition of nitric oxide/cyclic GMP-mediated relaxation by purified flavonoids, baicalin and baicalein, in rat aortic rings. Biochem Pharmacol 67: 787-794, 2004.

10. Schlossmann J, Feil R and Hofmann F: Signaling through NO and cGMP-dependent protein kinases. Ann Med 35: 21-27, 2003.

11. Ignarro LJ, Lippton H, Edwards JC, Baricos WH, Hyman AL, Kadowitz PJ and Gruetter CA: Mechanism of vascular smooth muscle relaxation by organic nitrates, nitrites, nitroprusside and nitric oxide: Evidence for the involvement of S-nitrosothiols as active intermediates. J Pharmacol Exp Ther 218: 739-749, 1981.

12. Rybalkin SD, Yan C, Bornfeldt KE and Beavo JA: Cyclic GMP phosphodiesterases and regulation of smooth muscle function. Circ Res 93: 280-291, 2003. 
13. Van Crombruggen $\mathrm{K}$ and Lefebvre RA: Nitrergic-purinergic interactions in rat distal colon motility. Neurogastroenterol Motil 16: 81-98, 2004.

14. Qu JT, Zhang DX, Liu F, Mao HP, Ma YK, Yang Y, Li CX, Qiu LZ, Geng X, Zhang JM, et al: Vasodilatory effect of wogonin on the rat aorta and its mechanism study. Biol Pharm Bull 38: 1873-1878, 2015.

15. Blair PJ, Rhee PL, Sanders KM and Ward SM: The significance of interstitial cells in neurogastroenterology. J Neurogastroenterol Motil 20: 294-317, 2014.

16. Gokce G, Bagcivan I, Kilicarslan H, Yildirim S, Gultekin YE and Sarioglu Y: Relaxation effects of adrenomedullin in isolated rabbit corpus cavernosum smooth muscle. BJU Int 93: 859-862, 2004.

17. Anwer K, Oberti C, Perez GJ, Perez-Reyes N, McDougall JK, Monga M, Sanborn BM, Stefani E and Toro L: Calcium-activated $\mathrm{K}+$ channels as modulators of human myometrial contractile activity. Am J Physiol 265: C976-C985, 1993.

18. Brayden JE: Potassium channels in vascular smooth muscle. Clin Exp Pharmacol Physiol 23: 1069-1076, 1996.

19. Kirber MT, Ordway RW, Clapp LH, Walsh JV Jr and Singer JJ: Both membrane stretch and fatty acids directly activate large conductance $\mathrm{Ca}\left({ }^{2+}\right)$-activated $\mathrm{K}^{+}$channels in vascular smooth muscle cells. FEBS Lett 297: 24-28, 1992.

20. Imai $T$, Okamoto $T$, Yamamoto $Y$, Tanaka H, Koike $K$, Shigenobu $\mathrm{K}$ and Tanaka Y: Effects of different types of $\mathrm{K}^{+}$ channel modulators on the spontaneous myogenic contraction of guinea-pig urinary bladder smooth muscle. Acta Physiol Scand 173: 323-333, 2001.

21. Herrera GM and Nelson MT: Differential regulation of SK and $\mathrm{BK}$ channels by $\mathrm{Ca}(2+)$ signals from $\mathrm{Ca}(2+)$ channels and ryanodine receptors in guinea-pig urinary bladder myocytes. J Physiol 541: 483-492, 2002.

22. Gebremedhin D, Kaldunski M, Jacobs ER, Harder DR and Roman RJ: Coexistence of two types of $\mathrm{Ca}(2+)$-activated $\mathrm{K}+$ channels in rat renal arterioles. Am J Physiol 270: F69-F81, 1996.

23. Pérez GJ, Toro L, Erulkar SD and Stefani E: Characterization of large-conductance, calcium-activated potassium channels from human myometrium. Am J Obstet Gynecol 168: 652-660, 1993.

24. Kurahashi M, Mutafova-Yambolieva V, Koh SD and Sanders KM: Platelet-derived growth factor receptor- $\alpha$-positive cells and not smooth muscle cells mediate purinergic hyperpolarization in murine colonic muscles. Am J Physiol Cell Physiol 307 C561-C570, 2014
25. Vogalis F and Goyal RK: Activation of small conductance $\mathrm{Ca}(2+)$-dependent $\mathrm{K}+$ channels by purinergic agonists in smooth muscle cells of the mouse ileum. J Physiol 502: 497-508, 1997.

26. Koh SD, Dick GM and Sanders KM: Small-conductance $\mathrm{Ca}(2+)$-dependent $\mathrm{K}+$ channels activated by ATP in murine colonic smooth muscle. Am J Physiol 273: C2010-C2021, 1997.

27. Bayguinov O, Hagen B, Bonev AD, Nelson MT and Sanders KM: Intracellular calcium events activated by ATP in murine colonic myocytes. Am J Physiol Cell Physiol 279: C126-C135, 2000.

28. Peri LE, Sanders KM and Mutafova-Yambolieva VN: Differential expression of genes related to purinergic signaling in smooth muscle cells, PDGFR $\alpha$-positive cells, and interstitial cells of Cajal in the murine colon. Neurogastroenterol Motil 25: e609-e620, 2013.

29. Hwang SJ, Blair PJ, Durnin L, Mutafova-Yambolieva V, Sanders KM and Ward SM: P2Y1 purinoreceptors are fundamental to inhibitory motor control of murine colonic excitability and transit. J Physiol 590: 1957-1972, 2012.

30. Lee H, Koh BH, Peri LE, Sanders KM and Koh SD: Functional expression of SK channels in murine detrusor PDGFR+ cells. J Physiol 591: 503-513, 2013.

31. Dick GM, Rossow CF, Smirnov S, Horowitz B and Sanders KM: Tamoxifen activates smooth muscle BK channels through the regulatory beta 1 subunit. J Biol Chem 276: 34594-34599, 2001.

32. Hagen BM and Sanders KM: Deglycosylation of the beta1-subunit of the BK channel changes its biophysical properties. Am J Physiol Cell Physiol 291: C750-C756, 2006.

33. Wang W, Huang H, Hou D, Liu P, Wei H, Fu X and Niu W: Mechanosensitivity of STREX-lacking BKCa channels in the colonic smooth muscle of the mouse. Am J Physiol Gastrointest Liver Physiol 299: G1231-G1240, 2010.

34. Yoon SB, Lee YJ, Park SK, Kim HC, Bae H, Kim HM, Ko SG, Choi HY, Oh MS and Park W: Anti-inflammatory effects of Scutellaria baicalensis water extract on LPS-activated RAW 264.7 macrophages. J Ethnopharmacol 125: 286-290, 2009.

35. Cuéllar MJ, Giner RM, Recio MC, Máñez S and Rios JL: Topical anti-inflammatory activity of some Asian medicinal plants used in dermatological disorders. Fitoterapia 72: 221-229, 2001 